\title{
Marmoset model takes centre stage
}

Newly created transgenic primate may become an alternative disease model to rhesus macaques.

Japanese researchers this week report the passing of a transgene from a primate to its offspring $^{1,2}$ (see pages 515 and 523). The work could establish marmosets as a model research organism to rival the more commonly used rhesus macaque, and usher in a new era of primates as human-disease models.

Erika Sasaki and her colleagues at the Central Institute for Experimental Animals in Kawasaki injected viral vectors with green fluorescent protein (GFP) into 91 marmoset embryos, then transferred the 80 healthy transgenic embryos to surrogate mothers. Five offspring were born - including twins Kei and Kou; keikou means fluorescence in Japanese all of which expressed the glowing transgene in some features at some point during development. Most exciting, says Sasaki, was the birth in April of a male produced by conventional in vitro fertilization using Kou's sperm. Since then, two more glowing second-generation marmosets have been born, although one died after being bitten by his mother.

"This is a great advancement, and it will bring more attention to primate models from people who don't normally think about primates," says Anthony Chan, a geneticist at the Yerkes National Primate Research Center of Emory University in Atlanta, Georgia.

Biomedical reseachers have long wanted primate models that can inherit and express introduced genes, as mice can. In 2001, a group led by Chan and Gerald Schatten, then at the Oregon Regional Primate Research Center in Portland and now at the University of Pittsburgh, Pennsylvania, introduced GFP into a rhesus macaque oocyte $^{3}$ and produced the animal named ANDi. In 2008, Chan reported rhesus macaques with the Huntington's disease gene ${ }^{4}$.

But passing transgenes to the

\section{"Marmosets will be}

\section{better as models}

than rodents, but are they good enough?"

next generation - the key to making a useful research model - had never been done. ANDi has not had any luck with natural breeding "perhaps owing to his short stature and relatively gentle demeanour", says Schatten, who is now working instead on intracytoplasmic sperm injection and cloning techniques.

With Chan's Huntington's monkeys, all but one of the first generation died from an early and extreme manifestation of the disease. Since then, three more have been born; Chan must wait another year or two to breed them.

Sasaki's marmosets could move more

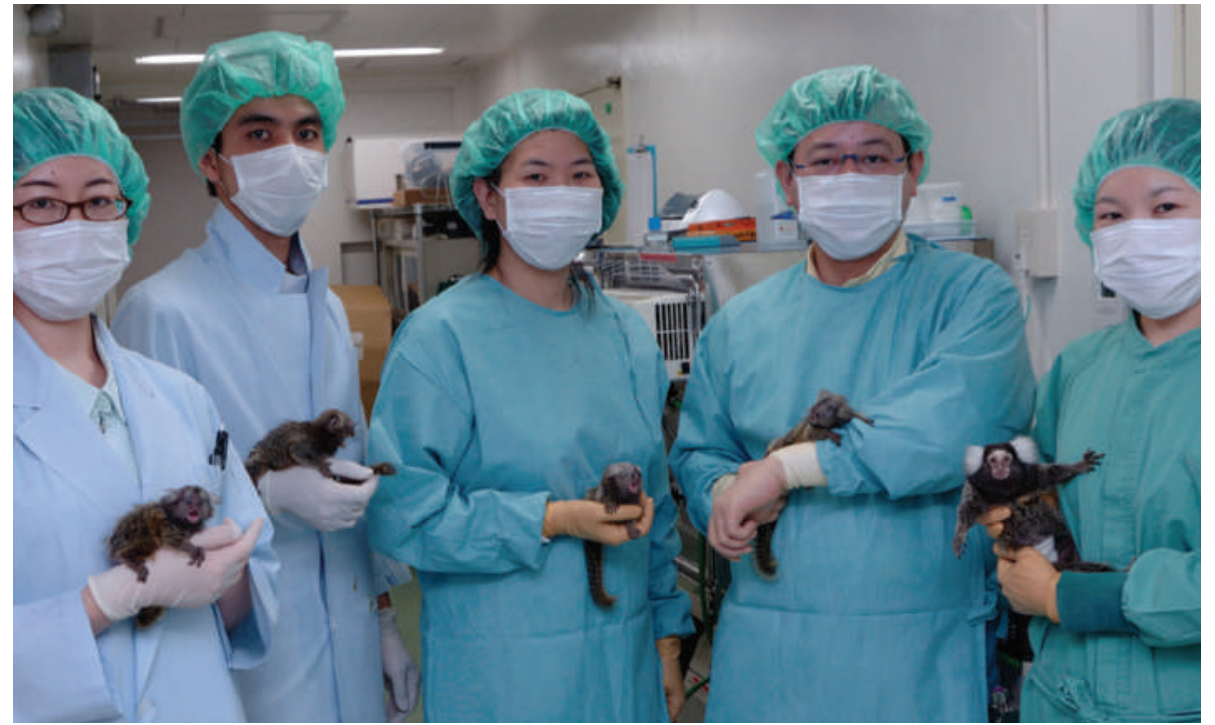

Erika Sasaki (centre) with transgenic marmosets Hisui, Banko, Wakaba, Kei and Kou.

quickly into disease modelling. Her first target is Parkinson's disease, but she is considering amyotrophic lateral sclerosis and Huntington's.

Other Japanese researchers are looking to expand on the work through the country's project in brain sciences, a 5-year programme for which 8 universities and institutes get an annual $¥ 600$ million (US\$6 million) to develop and use a "highly original model research animal". Tetsuo Yamamori, at the National Institute for Basic Biology in Okazaki, plans to introduce genes into the marmosets that control the expression of OCC-1, which he thinks is involved in vision.

\section{Monkey magic?}

Marmosets are small and relatively easy to handle. They reach sexual maturity in just over a year and a female can have up to 80 babies, compared with about 10 for the rhesus macaque. But the bottom line is whether marmosets can usefully model human disease. "They'll be better than rodents," says Chan. "But are they good enough?"

Marmosets, a New World monkey, are genetically further from humans than macaques. Nicole Déglon, of the French Atomic Energy Commission's Department of Medical Research in Gif-sur-Yvette, says that normal marmosets fail many cognitive ability tests that are used to judge the effects of conditions such as Alzheimer's disease. She says she stopped using marmosets because their brains are too small for positron emission tomography scans.

Tadashi Isa, a developmental physiologist at the National Institute for Physiological Sciences in Okazaki who is also a member of the brain-science programme, says marmoset research is likely to boom, but only as a complement to macaque research. Marmosets, he says, will be useful for studying cognitive and behavioural disorders because they share some social characteristics with humans, such as maintaining familial relationships. "But a higher brain function research paradigm has been established for things like attention and decision-making in the macaque," he says. "With marmosets, there is no history and no accumulation of knowledge."

The transgenic marmoset project is also likely to face challenges from bioethicists and animal-rights groups over creating a colony of animals born with a disease. "You must think of the cost-benefit," Sasaki responds. "If you can do it in rodents or in vitro, we should. But for many diseases, like Parkinson's, there is not a good model now."

David Cyranoski

1. Sasaki, E. et al. Nature 459, 523-527 (2009).

2. Schatten, G. \& Mitalipov, S. Nature 459, 515-516 (2009).

3. Chan, A. W. S., Chong, K. Y., Martinovich, C., Simerly, C. \& Schatten, G. Science 291, 309-312 (2001).

4. Yang, S.-H. et al. Nature 453, 921-924 (2008).

See Editorial, page 483, News \& Views, page 515, and Article, page 523. 